\title{
The role of hemorrhoidectomy in rectocele complicated by grade 3-4 hemorrhoids
}

\author{
O. Dandin $\cdot$ Y. Ozdemir $\cdot$ I. Sucullu
}

Received: 15 April 2012/Accepted: 7 August 2012/Published online: 6 September 2012

(C) Springer-Verlag 2012

Sir,

We read with great interest the article by Leal et al. [1] in which the authors concluded that the transanal repair of rectocele and rectal mucosectomy with a single circular stapler (TRREMS procedure) has satisfactory anatomic and functional results with a low incidence of postoperative pain and complications.

A rectocele is an abnormal sac-like projection of the anterior rectum into the posterior vaginal wall. Women commonly complain of stool trapping, a form of obstructed defecation, and report requiring digital pressure through the vagina in order to pass stools. The diagnosis of rectocele can be easily made on rectal examination. Defecography can be used for diagnosis or surgical decision making [2]. Stool trapping requiring digital evacuation or vaginal support and large protruding rectoceles are the major criteria for operative intervention [3]. Rectocele can be treated with a variety of local surgical approaches including the technique used by authors for rectocele complicated by rectal mucosal prolapse. Rectocele can be complicated by other perianal pathologies like hemorrhoids.

We would like to share our experience of patients with grade 3 and 4 hemorrhoids coexisting with symptomatic rectocele. Eight women presented with some complaint of stool trapping, constipation, anal swelling and bright red blood per rectum. Rectocele and grade 3-4 hemorrhoids were diagnosed based on the history, physical examination, colonoscopy and defecography. We planned a 3-quadrant hemorrhoidectomy with Liga-Sure as an initial treatment. After recovery, we saw that symptoms related to rectocele were improved in all of the patients, and defecography was normal. Postsurgical inflammation and fibrosis in 3-quadrant hemorrhoidectomy may increase the tightness in the anal mucosa and prevent bulging into the vagina. We think that a 3-quadrant hemorrhoidectomy rather than a circular mucosectomy causes more tightness in anal canal mucosa and better recovery for patients with coexisting rectocele.

Conflict of interest None.

\section{References}

1. Leal VM, Regadas FS, Regadas SM, Veras LR (2010) Clinical and functional evaluation of patients with rectocele and mucosal prolapse treated with transanal repair of rectocele and rectal mucosectomy with a single circular stapler (TRREMS). Tech Coloproctol 14:329-335

2. Mahieu PH, Pringot J, Bodart P (1984) Defecography II contribution to the diagnosis of defecation disorders. Gastrointest Radiol 9:253-261

3. Beck DE, Allen NL (2010) Rectocele. Clin Colon Rectal Surg 23:90-98

\footnotetext{
O. Dandin

Department of General Surgery, Bursa Military Hospital, 16070 Bursa, Turkey

Y. Ozdemir $(\bowtie) \cdot$ I. Sucullu

Department of General Surgery, Gulhane Military Medical

Academy, Haydarpasa Training Hospital, 34668 Kadikoy,

Istanbul, Turkey

e-mail: dryozdemir@yahoo.com
} 